Volume 5 Nomor 2, Agustus 2020, halaman 101-110

\title{
PENGGUNAAN MODEL PEMBELAJARAN TEAMS GAMES TOURNAMENTS BERBANTUAN LUDO MATH TERHADAP KEMAMPUAN PEMAHAMAN KONSEP BERDASARKAN TINGKAT DISPOSISI MATEMATIS SISWA
}

\author{
USING THE LUDO MATH ASSISTED TEAMS GAMES TOURNAMENTS \\ LEARNING MODEL THROUGH UNDERSTANDING CONCEPTS ABILITY BASED \\ ON STUDENTS' MATHEMATICAL DISPOSITION RATES
}

\author{
Nur Khodijah' ${ }^{1}$, Sri Hartini ${ }^{2}$, Wiwit Damayanti Lestari ${ }^{3}$ \\ 1,2,3 Universitas Wiralodra, Jln. Ir. H. Djuanda Km3 Singaraja Indramayu, Indonesia \\ Email: nurkhodijah0696@gmail.com, hartini5511@yahoo.co.id, \\ wiwitdamayantilestari@unwir.ac.id
}

\begin{abstract}
ABSTRAK
Penelitian ini bertujuan untuk; (1) mengetahui kemampuan pemahaman konsep berdasarkan Model Pembelajaran Teams Games Tournaments; (2) mengetahui kemampuan pemahaman konsep berdasarkan tingkat disposisi matematis; (3) mengetahui interaksi antara Model Pembelajaran Teams Games Tournaments dan tingkat disposisi matematis. Penelitian ini merupakan penelitian penelitian eksperimen yang dilakukan di MTsN 2 Indramayu pada semester ganjil. Populasi penelitian ini adalah seluruh kemampuan pemahaman konsep dan tingkat disposisi matematis siswa kelas VII MTsN 2 Indramayu tahun pelajaran 2019/2020. Sampel diambil sebanyak dua kelas menggunakan cluster random sampling dengan cara diundi. Berdasarkan hasil analisis data menggunakan ANAVA Dua Jalan by level, diperoleh kesimpulan sebagai berikut: (1) Terdapat perbedaan Kemampuan pemahaman konsep pada model pembelajaran Teams Games Tournamnets (TGT) berdasarkan penggunaan Ludo Math dan tanpa penggunaan Ludo Math. (2) Terdapat perbedaan kemampuan pemahaman konsep siswa kelompok tingkat disposisi matematis siswa tinggi dengan rendah. (3) Terdapat pengaruh interaksi (interaction effect).
\end{abstract}

Kata Kunci: Kemampuan Pemahaman Konsep, Disposisi Matematis Siswa, Model Pembelajaran Teams Games Tournaments (TGT), Ludo Math.

\section{ABSTRACT}

The aim of this research are: (1) to know understanding concept ability based on Teams Games Tournaments learning Model; (2) to know ability in understanding concept based on mathematical disposition level; (3) to know the interactions between Teams Games Tournaments learning Model and mathematical disposition level. This research used an experimental research. This research conducted at MTsN 2 Indramayu in second semester. The population of this study ere the whole understand concept ability and the level of mathematical disposition at VII grade of MTsN 2 Indramayu in 2019/2020 Academic Year. The Samples were taken by two classes using a random sampling cluster by draw. Based on the result of data analysis, the conclusions are obtained: (1) There were differences ability 
in understanding concept used Teams Games Tournamnets (TGT) learning model through Ludo Math and without it.; (2) There was a difference student's ability in understanding the concept of mathematical disposition level of high and low (between columns); (3) There were interaction effects.

Keywords: Ability of Understanding Concept, Student's Mathematical Disposition, Teams Games Tournaments (TGT), Ludo Math

How to Cite: Khodijah, N., Hartini, S., Lestari, W. D. (2020). Penggunaan Model Pembelajaran Teams Games Tournaments Berbantuan Ludo Math Terhadap Kemampuan Pemahaman Konsep Berdasarkan Tingkat Disposisi Matematis Siswa : Jurnal Matematika dan Pendidikan Matematika, Vol.5 No.2, 101- 110

DOI: $\underline{\text { https://doi.org/10.31943/mathline.v5i2.140 }}$

\section{PENDAHULUAN}

Sistem pembelajaran pada mata pelajaran matematika telah mengalami inovasi dan perkembangan sesuai dengan tantangan sekarang dan mendatang. Berkenaan dengan hal ini perlu diupayakan agar pembelajaran matematika dapat lebih mudah diterima oleh siswa sehingga mencapai hasil yang lebih optimal. Penguasaan materi dalam belajar matematika di sekolah, sebenarnya tidak lepas dari pemahaman konsep. Pemahaman konsep matematis dapat dilaksanakan dengan belajar matematika secara bermakna, tentunya para guru selalu berusaha meningkatkan pemahaman yang dicapai siswa dan tidak terbatas pada pemahaman yang bersifat dapat menghubungkan. Hal ini merupakan bagian yang paling penting dalam pembelajaran matematika menurut kurikulum 2013, pemahaman konsep sangat penting untuk dikuasai oleh siswa. Banyak kompetensi dasar dalam permendikbud nomor 24 tahun 2016 yang menekankan pentingnya pemahaman siswa terhadap materi pembelajaran. Dalam pembelajaran matematika juga dibebankan pentingnya pemahaman siswa terhadap materi matematika.

Pentingnya pemahaman konsep matematika terdapat pada peraturan Mentri Pendidikan Nasional (Permendiknas No. 22 tahun 2006) yaitu memahami konsep matematika, menjelaskan keterkaitan antar konsep dan mengaplikasikan konsep atau algoritma secara luwes, akurat, efisien dan tepat dalam pemecahan masalah. Sesuai dengan tujuan pembelajaran matematika di atas maka setelah proses pembelajaran siswa diharapkan dapat memahami suatu konsep matematika sehingga dapat menggunakan kemampuan tersebut dalam menghadapi masalah-masalah matematika. Pemahaman siswa terhadap konsepkonsep matematika saat ini masih lemah. Hal ini tercermin dari hasil survei yang dilakukan Trends in International Mathematics and Science Study (TIMSS) pada tahun 2016 yang 
menunjukkan bahwa Indonesia berada pada peringkat 36 dari 49 negara dengan skor ratarata 397 dari skor ideal 500 (Hadi \& Novaliyosi, 2019). Aspek yang dinilai dalam survei tersebut meliputi pengetahuan tentang fakta, prosedur, konsep, penerapan pengetahuan, dan pemahaman konsep. Salah satu faktor penyebab kemampuan pemahaman konsep matematis siswa yang rendah adalah pembelajaran yang diterapkan guru kurang efektif. Selain model pembelajaran yang kurang efektif, siswa biasanya hanya mencatat jawaban soal yang telah dibahas tanpa mengetahui maknanya (Muzayyanah, 2009).

Menurut Mahmudi (2010) menyatakan bahwa disposisi matematis merupakan salah satu faktor penunjang keberhasilan belajar matematika siswa. Disposisi matematis siswa dikatakan baik jika siswa menyukai masalah - masalah yang menantang serta melibatkan dirinya secara langsung dalam menemukan/ menyelesaikan masalah. Selain itu siswa merasakan dirinya mengalami proses belajar saat menyelesaikan tantangan tersebut. Dalam prosesnya siswa merasakan munculnya kepercayaan diri, pengharapan dan kesadaran untuk melihat kembali hasil berpikirnya. Disposisi matematis berkaitan dengan bagaimana siswa memandang dan menyelesaikan masalah; apakah siswa percaya diri, tekun, berminat, dan berpikir terbuka untuk mengeksplorasi berbagai alternatif strategi penyelesaian masalah. Disposisi juga berhubungan dengan kecenderungan siswa untuk mengungkapkan pemikiran mereka sendiri.

Kegiatan belajar matematika diupayakan terjadi interaksi aktif antar siswa baik secara fisik, intelektual maupun emosional. Keluhan yang sering disampaikan oleh siswa adalah tentang banyaknya rumus serta aturan yang harus dihafal. Selain itu matematika sulit untuk dimengerti dalam penggunaannya. Akibatnya siswa menjadi malas belajar dan berlatih atau merasa tidak senang terhadap mata pelajaran matematika sehingga menyebabkan hasil belajar matematika selalu saja masih kurang memuaskan, untuk mengatasi hal tersebut, telah banyak yang dilakukan guru baik dalam penyajian materi, pemilihan metode yang tepat dalam proses belajar. Hal ini dilakukan untuk meningkatkan pemahaman matematika agar lebih baik lagi. Model pembelajaran Teams Games Tournament (TGT) dalam pembelajaran matematika dapat dijadikan sebagai salah satu alternatif untuk meningkatkan prestasi dan motivasi belajar siswa (Susanti et al., 2020). Interaksi ini bisa dalam bentuk saling berdiskusi, bertanya dan bekerjasama dalam memahami atau mengerjakan tugas. Menurut Slavin (2014) Teams Games Tournament (TGT) merupakan metode pembelajaran kooperatif dengan langkah kerja presentasi di kelas, pembentukan kelompok, memainkan permainan serta melaksanakan turnamen, dan rekognisi kelompok. 
Adapun bantuan sebagai penunjang model pembelajaran Teams Games Tournament (TGT) dengan media Ludo Math, media ludo merupakan perkembangan dari permainan papan berpetak yang dirancang sebagai alat bantu media pembelajaran bagi peserta didik agar lebih mudah dalam memahami pembelajaran yang diajarkan. Permainan Ludo Math dipilih karena dalam metode ini seluruh siswa akan terlibat aktif dalam proses pembelajaran matematika dan penambahan Permainan Ludo Math akan menarik minat siswa untuk berpartisipasi aktif dalam proses pembelajaran matematika, media permainan ludo ini dapat menjadikan suasana belajar yang disenangi oleh peserta didik, meningkatkan kemampuan kognitif, perkembangan fisik, emosional serta dapat membentuk karakter positif. Guru akan membentuk kelompok berdasarkan kemampuan akademik yang heterogen dalam metode pembelajaran kooperatif ini, selanjutnya siswa akan belajar bersama dalam kelompok untuk menyelesaikan lembar kerja dari guru.

Permainan Ludo Math adalah permainan Ludo yang telah dimodifikasi dengan memasukkan unsur pelajaran matematika ke dalam permainan ini, dalam turnamen setiap siswa akan memainkan Ludo Math. Cara memainkan Ludo Math adalah dengan menggerakkan pion untuk secepat mungkin mencapai home dengan cara menjawab peetanyaan-pertanyaan yang telah disediakan. Siswa akan berusaha untuk menjadi yang tercepat dan terbaik agar mendapatkan poin bagi kelompok mereka, hal ini juga akan meningkatkan kemampuan pemahaman konsep siswa.

Berdasarkan urian diatas, maka tujuan utama penelitian ini adalah untuk: (1) Mengetahui perbedaan kemampuan pemahaman konsep berdasarkan Model Pembelajaran Teams Games Tournaments; (2) Mengetahui perbedaan kemampuan pemahaman konsep berdasarkan tingkat disposisi matematis; (3) Mengetahui interaksi antara Model Pembelajaran Teams Games Tournaments dan tingkat disposisi matematis .

\section{METODE PENELITIAN}

Metode penelitian yang digunakan dalam penelitian ini adalah metode penelitian eksperimen. Kedua kelas eksperimen diberikan angket Disposisi Matematis, setelah itu kedua kelas sampel masing-masing diberi perlakuan, kelas pertama menggunakan model pembelajaran Teams Games Tournaments (TGT) berbantuan Ludo Math pada dan kelas kedua menggunakan model pembelajaran Teams Games Tournaments (TGT) tanpa Ludo Math. Setelah diberi perlakuan kedua kelas sampel diberikan tes akhir untuk mengetahui kemampuan pemahaman konsep siswa. Adapun desain penelitian yang digunakan adalah: (dimodifikasi dari Aan Juhana Senjaya, 2017) 

Siswa

$\begin{array}{lllll}R: & \mathbf{B}_{1} & \mathrm{O}_{1} & \mathrm{~K}_{1} & \mathrm{O}_{2} \\ & & & \mathrm{~K}_{2} & \\ \mathrm{R}: & \mathbf{B}_{2} & \mathrm{O}_{1} & \mathrm{~K}_{1} & \mathbf{O}_{2} \\ & & & \mathrm{~K}_{2} & \end{array}$

Populasi dalam penelitian ini adalah seluruh kemampuan pemahaman konsep siswa kelas VII MTsN 2 Indramayu tahun ajaran 2019/2020 yang terbagi menjadi enam kelas , yaitu VII A, VII B, VII C, VII D, VII E, dan VII F. Teknik pengambilan sampel dalam penelitian ini menggunakan cluster random sampling, karena populasi sudah dikelompokan dalam enam kelas dan akan dipilih dua kelas sebagai sampel. Setelah dilakukan pengundian, terpilih kelas VII E dan VII C. Dengan demikian kelas VII E menggunakan model pembelajaran Teams Games Tournaments (TGT) berbantuan Ludo Math, dan kelas VII C menggunakan model pembelajaran Teams Games Tournaments (TGT) tanpa Ludo Math.

Instrumen yang digunakan untuk mengukur disposisi matematis berupa angket, sedangkan untuk mengukur kemampuan pemahaman konsep menggunakan tes uraian. Proses validasi empiris adalah melalui uji perhitungan koefisien validitas setiap butir angket maupun butir soalnya dengan menggunakan rumus koefisien korelasi product moment dari Person (Karl Pearson). Uji coba instrument dilakukan pada kelas yang bukan merupakan kelas sampel dan kelas tersebut sudah pernah diajarkan materi persamaan dan pertidaksamaan linear satu variabel, oleh sebab itu peneliti memilih kelas VIII D di MTsN 2 Indramayu tahun pelajaran 2018/2019 dengan empat soal uraian, diperoleh hasil uji coba instrumen sebagai berikut:

Tabel 1

\begin{tabular}{|c|c|c|c|c|c|}
\hline \multicolumn{5}{|c|}{ Hasil Uji Coba validitas Instrumen Kemampus } & \multirow{2}{*}{$\begin{array}{l}\text { Pemaham } \\
\text { Keterangan } \\
\end{array}$} \\
\hline No Soal & Interpertasi & $\mathbf{r}_{\mathrm{xy}}$ & $t_{\text {obs }}$ & $t_{(0,05 ; 25)}$ & \\
\hline 1 & $\begin{array}{l}\text { Sangat } \\
\text { Tinggi }\end{array}$ & 0,86 & 8,43 & & Valid \\
\hline 2 & Tinggi & 0,68 & 4,64 & & Valid \\
\hline 3 & $\begin{array}{l}\text { Sangat } \\
\text { Tinggi }\end{array}$ & 0,87 & 8,82 & 1,71 & Valid \\
\hline 4 & Sedang & 0,56 & 3,38 & & Valid \\
\hline
\end{tabular}

Dari hasil uji coba instrument diatas, dapat dilihat bahwa instrument kemampuan pemahaman konsep yang terdiri dari empat soal, soal-soal tersebut dinyatakan valid. Oleh karena itu peneliti dapat menggunakan keempat soal tersebut sebagai instrument kemampuan pemahaman konsep siswa. Data yang diperlukan dalam penelitian ini akan dikumpulkan dengan teknik pemberian tes kemampuan pemahaman konsep siswa setelah selesai pemberian materi belajar, tes tersebut dalam bentuk soal uraian dan angket untuk 
mengukur tingkat disposisi matematis dalam bentuk angket dengan kriteia yang sama antara kelas eksperimen dan kontrol.

\section{HASIL DAN PEMBAHASAN}

Analisis data yang digunakan untuk penelitian ini yakni berupa Analisis Varian Dua Jalan (Two Way Analysis of Variance) atau biasa disebut ANAVA Dua Jalan 2x2 by level. Tetapi terlebih dahulu peneliti melakukan uji prasyarat yaitu melakukan uji normalitas dengan menggunakan Uji Kolmogorov-Smirnov, lalu melakukan uji homogenitas dengan menggunakan uji Bartlet,

Berikut ini merupakan hasil perhitungan uji normalitas dengan menggunakan Kolmogorov-Smirnov.

Tabel 2

Hasil Uji Normalitas Kolmogorov_Smirnov Pada Tiap Kelompok Sampel Penelitian

\begin{tabular}{cccccc}
\hline $\begin{array}{c}\text { Kelompok } \\
\text { Data }\end{array}$ & \multicolumn{1}{c}{$\mathrm{D}_{0}$} & $\begin{array}{c}\text { Taraf } \\
\text { signifikan }\end{array}$ & $\mathrm{N}$ & $\mathrm{D}_{\text {kritis }}$ & Kriteria \\
\hline $\mathrm{B}_{1} \mathrm{~K}_{1}$ & 0.324 & & 13 & 0.361 & Normal \\
$\mathrm{B}_{1} \mathrm{~K}_{2}$ & 0.311 & 0,05 & 8 & 0.457 & Normal \\
$\mathrm{B}_{2} \mathrm{~K}_{1}$ & 0.197 & & 13 & 0.361 & Normal \\
$\mathrm{B}_{2} \mathrm{~K}_{2}$ & 0.194 & & 12 & 0.375 & Normal \\
\hline
\end{tabular}

Berdasarkan data kemampuan pemahaman konsep siswa diatas, untuk tiap kelompok sampel penelitian mempunyai kriteria $D_{o}<D_{k}$ maka dapat disimpulkan bahwa populasi berdistribusi normal.

Uji prasyarat yang kedua yaitu uji homogenitas. Uji homogenitas yang dilakukan yaitu dengan menggunakan uji Bartlet. Berdasarkan hasil perhitungan uji Bartlet diperoleh hasil sebagai berikut. diperoleh $\mathrm{x}^{2}{ }_{0}=0,325, \mathrm{x}^{2}{ }_{\mathrm{k} 1}=0.001$, dan $\mathrm{x}^{2}{ }_{\mathrm{k} 2}=5.024$. Akibatnya $\mathrm{x}_{\mathrm{k} 1}$ $\leq \mathrm{x}^{2}{ }_{0} \leq \mathrm{x}^{2}{ }_{\mathrm{k} 2}$, maka dapat disimpulkan bahwa varian homogen. Setelah melakukan uji normalitas menggunakan Kolmogorov-Smirnov, uji homogenitas menggunakan Uji Bartlett, diperoleh bahwa varian kelompok homogen. Kemudian melakukan Uji ANAVA dua jalan, diperoleh data sebagai berikut:

\section{Tabel 3}

Hasil Perhitungan Anava Dua Jalan

\begin{tabular}{ccccccc}
\hline $\begin{array}{c}\text { Sumber } \\
\text { Variansi }\end{array}$ & \multirow{2}{*}{$\mathrm{JK}$} & $\mathrm{Db}$ & \multirow{2}{*}{$\mathrm{RJK}$} & $\mathrm{Fo}$ & \multicolumn{2}{c}{ Fkritis } \\
& & & & & $\mathrm{Fk}_{1}$ & $\mathrm{Fk}_{2}$ \\
\hline Antar B & 984.08 & 1 & 984.08 & 7.40 & 0.0010 & 5.404 \\
Antar K & 1066.16 & 1 & 1066.16 & 8.02 & 0.0010 & 5.404 \\
Antar & & & & - & & \\
Interaksi BxK & -35.36 & 1 & -35.36 & 0.27 & 0.0010 & 5.404 \\
Dalam (SEM) & 5583.49 & 42 & 132.94 & & & \\
Total & 7598.37 & 45 & & & & \\
\hline
\end{tabular}


Berdasarkan hasil perhitungan ANAVA di atas, diperoleh hasil sebagai berikut: Pengujian terhadap hipotesis utama (main effect) untuk mengetahui perbedaan Kemampuan pemahaman konsep pada model pembelajaran Teams Games Tournamnets (TGT) berdasarkan penggunaan Ludo Math dan tanpa penggunaan Ludo Math. Pada data antar baris diatas, $F_{0}=7,40, F_{k 1}=0,001$, dan $F_{k 2}=5,404$. Karena $0,001 \leq F_{0}=7,40 \leq 5,404$, dengan demikian, perbedaan kemampuan pemahaman konsep siswa kelompok Model Pembelajaran TGT dengan penggunaan Ludo Math dan tanpa penggunaan Ludo Math signifikan. Hasil penelitian ini sejalan dengan hasil penelitian yang dilakukan oleh Susan Mardiana (2015) pada kelas X AK 2 SMK Negeri 1 Godean juga menyatakan penerapan metode pembelajaran kooperatif tipe Teams Games Tournaments (TGT) dengan permainan ludo akuntansi dapat meningkatkan aktivitas belajar akuntansi. Hal ini dibuktikan disetiap indikator aktivitas belajar akuntansi dari siklus I ke siklus II. peningkatan persentase rata-rata aktivitas belajar akuntansi sebesar 19,29\% berasal dari persentase rata-rata Aktivitas Belajar Akuntansi dari siklus I 69,35\% menjadi 88,64\% pada siklus II. Terdapatnya turnamen berbantuan Ludo Math dapat membuat siswa lebih memahami konsep dalam pembelajaran. Penggunaan media pembelajaran yang kreatif dan inovatif dapat memberikan pengaruh positif bagi peserta didik untuk meningkatkan kualitas belajarnya sangatlah diperlukan. Penanaman moral kepada peserta didik sangat baik apabila diterapkan pada saat proses pembelajaran dikelas berlangsung. Seperti terlihat pada gambar berikut

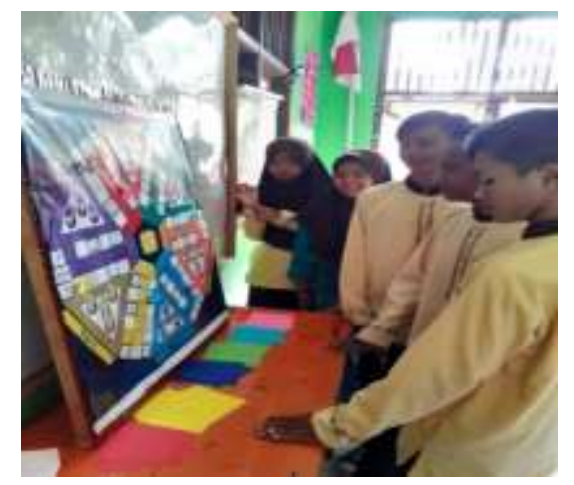

\section{Gambar 1. Siswa Aktif dalam Pembelajaran berbantuan Ludo Math}

Hasil Pengujian terhadap hipotesis utama (main effect) untuk mengetahui perbedaan kemampuan pemahaman konsep siswa kelompok tingkat disposisi matematis siswa tinggi dengan rendah (antar kolom). Pada data antar kolom diatas, $F_{0}=8,02, F_{k 1}=0,001$, dan $F_{k 2}=$ 5,404. Karena $0,001 \leq \mathrm{F}_{0}=8,02 \leq 5,404$, dengan demikian, perbedaan kemampuan pemahaman konsep siswa kelompok Tingkat Disposisi Matematis : tinggi dengan rendah signifikan. Hasil penelitian ini sejalan dengan Sumarmo (2012) bahwa seseorang yang 
memiliki disposisi matematis yang tinggi akan membentuk individu yang tangguh, ulet, bertanggungjawab, memiliki motif berprestasi yang tinggi, serta membantu individu mencapai hasil terbaiknya. Pada hasil penelitian yang lain, pembelajaran dengan muatan disposisi matematik dapat membantu mempengaruhi kemampuan pemecahan masalah siswa (Ismunandar, 2016). Perubahan kecenderungan siswa dalam memandang dan bersikap terhadap matematika, serta bertindak ketika belajar matematika dapat dilihat ketika siswa dapat menyelesaikan permasalahan, sikap dan keyakinannya sebagai seorang pelajar menjadi lebih positif. Terlihat pada hasil kemampuan pemahaman konsep siswa sebagai berikut:

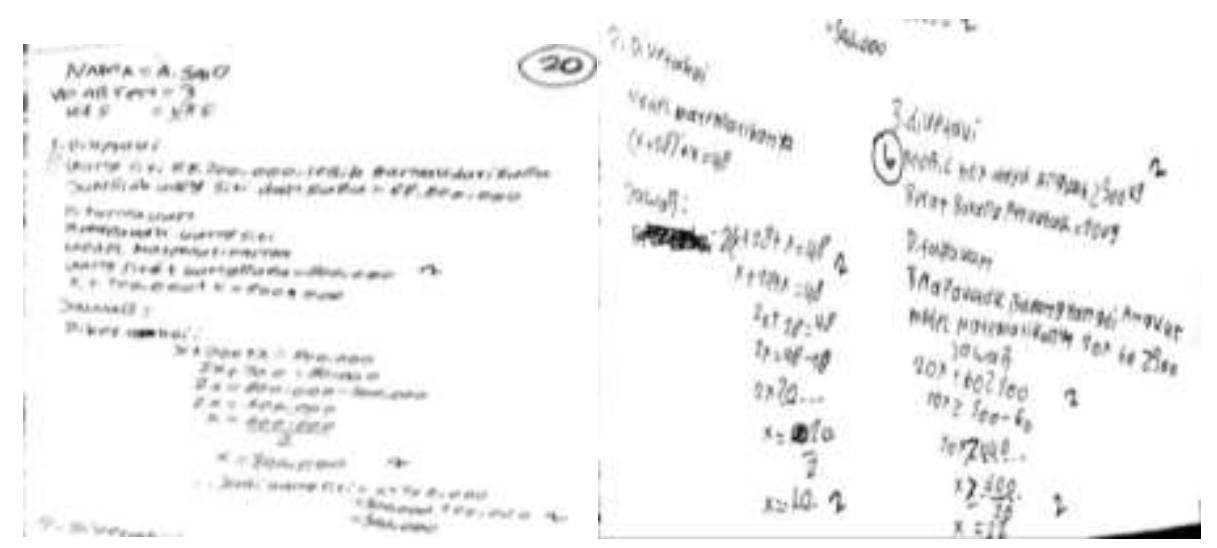

Gambar 2 Hasil Kemampuan Pemahaman Konsep Siswa

Pengujian terhadap hipotesis statistik pengaruh interaksi (interaction effect). Pada interaksi diatas $F_{0}=-0,27, F_{k 1}=0,001$, dan $F_{k 2}=5,404$. Karena $F_{0}=-0,27<0$ maka tolak $\mathrm{H}_{0}$. Dengan demikian, perbedaan kemampuan pemahaman konsep siswa berdasarkan interaksi antara model pembelajaran Teams Games Tournaments (TGT) dengan tingkat disposisi matematis signifikan.

Kemudian dilanjutkan uji lanjut (Pos-hoc test) dari Scheffe. Analisis data yang dilakukan, menggunkan bantuan software PESTRIPP (Senjaya, 2017) dengan taraf signifikan $\alpha=0,05$. Berdasarkan hasil perhitungan uji lanjut Post Hock dari scheffe diperoleh hasil sebagai berikut: (1) Perbedaan rerata kemampuan pemahaman konsep antara kelompok tingkat disposisi tinggi dan tingkat disposisi rendah pada model pembelajaran Teams Games Tournaments dengan penggunaan Ludo Math signifikan karena $t_{0}=2,51>t_{k}=1,85$; (2) Perbedaan rerata kemampuan pemahaman konsep antara kelompok tingkat disposisi tinggi dan tingkat disposisi rendah pada model pembelajaran Teams Games Tournaments dengan tanpa penggunaan Ludo Math signifikan karena $\mathrm{t}_{0}=1,21<\mathrm{t}_{\mathrm{k}}=1,85$; (3) Perbedaan rerata kemampuan pemahaman konsep antara kelompok model pembelajaran Teams Games 
Tournaments dengan penggunaan Ludo Math dan tanpa penggunaan Ludo Math pada kelompok tingkat disposisi matematis siswa tinggi, signifikan karena $t_{0}=2.55>t_{k}=1,85$; (4) Perbedaan rerata kemampuan pemahaman konsep antara kelompok model pembelajaran Teams Games Tournaments dengan penggunaan Ludo Math dan tanpa penggunaan Ludo Math pada kelompok tingkat disposisi matematis siswa rendah, tidak signifikan karena $\mathrm{t}_{0}=$ $0,79<\mathrm{t}_{\mathrm{k}}=1,85$.

\section{KESIMPULAN}

Berdasarkan hasil penelitian dan pembahasan, maka dapat disimpulkan bahwa: (1) Terdapat perbedaan kemampuan pemahaman konsep siswa kelompok Model Pembelajaran TGT dengan penggunaan Ludo Math dan tanpa penggunaan Ludo Math signifikan; (2) Terdapat perbedaan kemampuan pemahaman konsep siswa kelompok Tingkat Disposisi Matematis : tinggi dengan rendah signifikan; (3) Terdapat perbedaan kemampuan pemahaman konsep siswa berdasarkan interaksi antara model pembelajaran Teams Games Tournaments (TGT) dengan tingkat disposisi matematis signifikan.

Dari kesimpulan diatas, saran yang dapat penulis sampaikan yaitu: (1) Untuk Guru, Suasana kelas sangat berpengaruh untuk menarik perhatian siswa untuk proses pembelajaran, dengan adanya permainan atau turnamen pada kelas siswa dapat lebih bersemangat dalam proses pembelajaran. Sebaiknya dalam pembelajaran disposisi matematis siswa lebih diperhatikan sehingga kemampuan pemahaman konsep dapat tercapai, Model pembelajaran Teams Games Tournaments (TGT) dengan Penggunaan Ludo Math dapat menjadi salah satu alternatif bagi guru untuk menerapkannya dikelas, khususnya untuk meningkatkan kemampuan pemahaman konsep siswa, dengan menggunakan Ludo Math juga dapat menciptakan suasana kelas yang menyenangkan dalam proses pembelajaran; (2) Untuk Pembaca, Diharapkan skripsi ini dapat menambah wawasan dan pengetahuan yang berkaitan dengan kemampuan pemahaman konsep siswa pada Model pembelajaran Teams Games Tournaments (TGT) dengan penggunaan Ludo Math berdasarkan tingkat disposisi matematis siswa; (3) Untuk penelitian lebih lanjut. Karena adanya keterbatasan dalam penelitian ini, diharapkan dapat menindaklanjuti penelitian ini dengan waktu yang sesuai, dikarenakan dalam penelitian ini hanya dilaksanakan dua pertemuan, pertemuan petama menyampaikan materi saja membutuhkan 1 jam lebih pelajaran, sehingga untuk bermain Ludo Math kurang terlaksana dengan baik, pada pertemuan kedua jadwal belajar terpotong oleh kegiatan rutin sekolah dan itu diluar jadwal, maka peneliti baiknya harus menanyakan kegiatan rutin sebelum jam pelajaran, sehingga jam pelajaran yang kita rencakan dapat terlaksana dengan baik. 


\section{UCAPAN TERIMAKASIH}

Ucapan terimakasih penulis ungkapan kepada Bapak Drs. Akhmad Fauji, MA selaku Kepala Sekolah MTSN 2 Indramayu yang telah memberikan kesempatan kepada penulis untuk melakukan penelitian; Bapak M.Mantik DJ, S.Pd.M.Si selaku Guru Mata Pelajaran Matematika kelas VII yang banyak membantu penulis dalam penelitian. Ungkapan teimakasih juga Ibu Dr. Hj.Sri Hartini, M.Pd., selaku Dosen Pembimbing I dan Ibu Wiwit Damayanti L, S.Pd,. M.Pd., selaku Dosen Pembimbing II yang selalu memotivasi, meluangkan waktunya untuk memberikan banyak ilmu melalui bimbingan, serta dengan penuh perhatian memberikan arahan, kritik, dan saran kepada penulis selama pembuatan skripsi sehingga penulis dapat menyelesaikan skripsi sehingga penulis dapat menyelesaikan skripsi dengan baik.

\section{DAFTAR PUSTAKA}

Depdiknas. 2006. Peraturan Menteri Pendidikan Nasional Republik Indonesia Nomor 22 Tahun 2006 Tentang Standar Isi untuk Satuan Pendidikan Dasar dan Menengah. BSNP: Jakarta.

Hadi, S, \& Novaliyosi. 2019 TIMSS INDONESIA (Trends In International Mathematics And Science Study). Prosiding Seminar Nasional \& Call For Papers. Tasikmalaya. Universitas Siliwangi: 562-569.

Mahmudi, A. 2010. Tinjauan Asosiasi antara Kemampuan Pemecahan Masalah Matematis dan Disposisi Matematis. Seminar Nasional. Universitas Negeri Yogyakarta: 1-11.

Mardiana, S. 2014. Penerapan Metode Pembelajaran Kooperatif Tipe Teams Games Tournament (TGT) dengan Permainan Ludo Akuntansi untuk meningkatkan Aktivitas Belajar Akuntansi Siswa kelas X AK 2 SMK Negeri 1 Godean Tahun Pelajaran 2014/2015. Skripsi. Universitas Negeri Yogyakarta (Tidak diterbitkan).

Ismunandar, D. (2016). Pembelajaran Bermuatan Disposisi Matematika Pada Kelas X Program IPS. Mathline : Jurnal Matematika Dan Pendidikan Matematika, 1(2), 7082.

Susanti, E., Nandang, N., \& Puri, I. D. (2020). Penggunaan Model Pembelajaran Teams Games Tournament Untuk Meningkatkan Keaktifan Dan Hasil Belajar Siswa Pada Materi Aplikasi Barisan. Mathline : Jurnal Matematika Dan Pendidikan Matematika, 5(1), 37-46.

Muzayyanah, A. 2009. Peningkatan Kemampuan Komunikasi Matematika Siswa Dalam Pembelajaran Matematika Melalui Model Pembelajaran Kooperatif Tipe Think Pair Share (TPS) di SMA Negeri 1 Godean. Prosiding Seminar Nasional Pembelajaran Matematika sekolah. Universitas Negeri Yogyakarta : 300-318.

Senjaya, A.J. 2017. Statistik Terapan untuk Riset Bidang pendidikan dan Pengajaran. FKIP Press. Indramayu.

Slavin, R, E. 2014. Cooperative Learning Teori, Riset, dan Praktik. (Alih bahasa: Narulita Yusron). Bandung: Nusa Media.

Sumarmo, U. 2010. Berfikir dan Disposisi Matematik. Bandung : FPMIPA UPI. 